\title{
A psicofarmacologização da infância e o modelo de ação da droga centrado na doença
}

Sandra Caponi'

\section{Resumo}

A prescrição e a ampla aceitação do uso de antipsicóticos clássicos e atípicos na infância e na adolescência foi reivindicada aduzindo a suposta função terapêutica e curativa dessas drogas. Tomando como ponto de partida a distinção de dois modelos explicativos de ação dos psicofármacos, um centrado na doença e outro centrado na droga, analiso de que modo a indústria farmacêutica contribuiu, com suas estratégias publicitárias, com a divulgação de uma narrativa triunfalista que naturalizou o uso de antipsicóticos como cura para doenças psiquiátricas. Os dois psicofármacos analisados são a clorpromazina, um antipsicótico clássico, e a risperidona, um antipsicótico atípico de última geração.

Palavras-chave: Antipsicóticos clássicos. Antipsicóticos atípicos. Infância. Indústria farmacêutica. Medicalização.

\section{O modelo centrado na doença e o modelo centrado na droga}

Proponho analisar aqui o alcance de dois modelos explicativos da ação das drogas psiquiátricas identificados por Joanna Moncrieff (2008). As duas estratégias explicativas são: o modelo centrado na doença e o modelo centrado na droga. O primeiro modelo parte da identificaçáo da psiquiatria com a medicina geral, supóe a existência de uma doença biológica, uma alteração orgânica que os fármacos poderiam reverter completamente

I Professora titular do Departamento de Sociologia e Ciência Política da Universidade Federal de Santa Catarina (UFSC). Pesquisadora de CNPq. E-mail: sandracaponi@gmail.com.

\section{(c))Er}

Direito autoral e licença de uso: Este artigo está licenciado sob uma Licença Creative Commons. Com essa licença você pode compartilhar, adaptar, para qualquer fim, desde que atribua a autoria da obra, forneça um link para a licença, e indicar se foram feitas alterações. 
ou, então, anular a constelação de sintomas que a definem. Esse é o modelo defendido pelo NIMH, e particularmente por Insel (INSEL, 2010). De acordo com esse modelo, os psicofármacos têm uma forma de ação idêntica aos outros medicamentos, cuja função seria, como ocorre com os antibióticos, reverter as causas orgânicas da doença, ou, como ocorre com os analgésicos, controlar os sintomas de uma alteração orgânica.

No caso dos psicofármacos, esse modelo afirma que as drogas teriam a função de restabelecer o equilíbrio neuroquímico que se encontra alterado em diversos transtornos psiquiátricos. É por essa razão que vários autores, no momento da aparição da primeira droga psiquiátrica descoberta em 1954, a clorpromazina, estabeleceram uma analogia entre a descoberta dessa substância e a da penicilina. Essa analogia foi substituída hoje por outra, mais utilizada e repetida, que parece ser também mais apropriada: a identificação entre a ação dos psicofármacos e a insulina. Aqui já não se faz referência a uma doença infecciosa que pode ser definitivamente curada, mas a uma doença como a diabetes, considerada crônica e que exige um tratamento contínuo.

Um exemplo de medicina que os psiquiatras costumam citar, num esforço para reforçar o modelo centrado na doença, é o uso de insulina para a diabetes. Ao substituir a dificuldade do corpo de produzir o hormônio da insulina, a terapia com insulina de substituição ajuda a restabelecer o corpo para o estado normal. Mesmo os tratamentos sintomáticos, como os analgésicos, atuam de maneira focada na doença, porque produzem seus efeitos neutralizando alguns dos processos fisiológicos que produzem a dor. (MONCRIEFF, 2013c).

De acordo com esse modelo, os psicofármacos agiriam equilibrando um sistema nervoso doente ou anormal. Assim, os efeitos desejados dos psicofármacos são aqueles que revertem o processo da doença e seus sintomas manifestos. São considerados como efeitos secundários, colaterais e indesejados, os efeitos produzidos pelo fármaco que não estão diretamente vinculados à desaparição dos sintomas, por exemplo, lentidáo psicomotora, confusão mental, insônia, aumento de apetite e de peso, dentre outros.

Porém, o sustento epistemológico desse modelo explicativo centrado na doença é extremamente frágil. Isso ocorre porque não existem estudos científicos confiáveis que nos permitam entender as causas neuroquímicas ou genéticas das doenças psiquiátricas. Não conhecemos as redes causais 
que explicariam quais são as alteraçóes cerebrais ou os desequilíbrios neuroquímicos que constituem a etiologia das patologias psiquiátricas. Não existem estudos de laboratório com modelos animais que possam ser considerados conclusivos, não existem imagens cerebrais nem estudos comparativos que indiquem uma diferença entre o nível de dopamina de um sujeito diagnosticado com esquizofrenia e um sujeito saudável.

Moncrieff (2013c) opóe a esse modelo, que classicamente define o uso de fármacos em diferentes ramos da medicina geral, outra abordagem que denomina como "modelo centrado nas drogas". Trata-se de um modelo que se aplica exclusivamente aos psicofármacos, pois não pode ser transposto para os medicamentos utilizados em outros campos da medicina. De acordo a este modelo as drogas psiquiátricas, longe de corrigir um estado anormal ou restabelecer um equilíbrio neuroquímico perdido, têm a função de induzir alterações cerebrais, produzindo um estado anormal ou alterado. Para Moncrieff, as drogas psiquiátricas têm um modo de ação com base na intoxicaçáo cerebral, do mesmo modo que ocorre com outras substâncias psicoativas, como o álcool, a heroína, o ópio ou outras drogas de uso recreativo. Nesse modelo não existe referência a uma doença específica, nem a um conjunto de sintomas, pois essas drogas têm uma ação semelhante para qualquer consumidor, independentemente de ele ter ou não um diagnóstico psiquiátrico.

Isso é o que ocorre, por exemplo, com estimulantes como a Ritalina $a^{\circ} \mathrm{O}$ modelo centrado na doença afirma que o metilfenidato pode restabelecer um equilíbrio neuroquímico, especificamente em relação a uma diminuição dos níveis de dopamina, serotonina ou noradrenalina no Sistema Nervoso Central, que seria a causa hipotética do Transtorno de Déficit de Atenção e Hiperatividade (TDAH). Porém, é possível observar que essa droga age do mesmo modo e tem os mesmos efeitos, tanto em crianças e adolescentes diagnosticados com TDAH, como naqueles que não têm diagnóstico psiquiátrico e simplesmente desejam aumentar seu poder de concentração, por exemplo, antes de um exame. Isso ocorre porque, de acordo com Moncrieff (2013c), Breggin (2008), Whitaker (2010), dentre outros, as drogas psiquiátricas, do mesmo modo que a cocaína, exercem seus efeitos, ainda que de modo diferente, sobre qualquer 
consumidor, independentemente de ele haver sido diagnosticado ou não com um transtorno mental.

Os psicofármacos são substâncias psicoativas que agem modificando o funcionamento cerebral, produzindo alteraçóes comportamentais, intelectuais e afetivas. Cada uma dessas substâncias psicoativas terá um efeito diferente, do mesmo modo que não são idênticos os efeitos provocados pelo consumo de diferentes drogas recreativas, tais como álcool, cocaína ou maconha. Alguns efeitos serão considerados benéficos para as pessoas que consumem essas drogas, auxiliando-os a relaxar, a se concentrarem, a se sentirem mais ativos e estimulados. Para muitos, esses efeitos benéficos são superiores aos efeitos colaterais ou negativos que essas drogas produzem. Por esse motivo, Moncrieff e Cohen (2005) argumentam que, se nos situarmos no modelo centrado nas drogas, poderemos dizer que os efeitos psicoativos produzidos por algumas drogas podem ser terapeuticamente úteis em certas situaçóes.

Porém, e independentemente de sua utilidade imediata, o certo é que as drogas psiquiátricas não permitem restabelecer nenhum equilíbrio neuroquímico perdido, nem normalizar as funçóes cerebrais, mas agem induzindo e produzindo alteraçóes no cérebro. Elas atuam criando um estado cerebral anormal ou alterado, que pode ser de utilidade para suprimir as manifestaçóes ou os sintomas que, desde o DSM-III, foram definidos como indicadores de um transtorno mental. De modo que, se desconhecemos os mecanismos cerebrais que provocaram a patologia, podemos, no entanto, conhecer os efeitos que as drogas psiquiátricas provocam no cérebro das pessoas tratadas.

O que Moncrieff (2013c) propóe com essa distinção, aparentemente simples, entre dois modelos explicativos, não é outra coisa que um convite a "falar claro" ou a reconhecer o que efetivamente acontece no campo da psicofarmacologia. O modelo centrado na doença, hegemônico e difundido no campo da psiquiatria, parece ter fracassado a partir do momento que, até hoje, não foi possível identificar a etiologia das psicoses nem de outros transtornos psiquiátricos. No entanto, os defensores e propagadores do modelo centrado na doença insistem em afirmar que os psicofármacos são eficientes para tratar patologias mentais, para restituir a normalidade perdida ou para reequilibrar alteraçóes neuroquímicas. Ao contrário, 
atrever-se a falar das drogas psiquiátricas a partir do efeito que elas provocam nos usuários significa reconhecer que a prescrição de psicofármacos encontra seu fundamento nos efeitos que o fármaco produz, e não na capacidade de reverter um estado patológico. Dito de outro modo, isso significa afirmar que os psicofármacos são mais próximos das drogas de consumo social ou lúdico, como o álcool, que de medicamentos como a insulina, a penicilina ou a Aspirina (ácido acetilsalicílico).

Ainda que o álcool possa operar como uma substância que neutraliza a inibição e permite uma interação social mais fluida em determinados âmbitos e contextos, não é possível entender sua ação a partir do modelo centrado na doença. Ninguém imaginará que a assim chamada "fobia social" ou as simples dificuldades sociais de interação, para as quais o álcool pode ser um excelente auxiliar, se deva a que essa substância permite corrigir um déficit de álcool no cérebro ou restaurar um equilíbrio químico alterado. Porém, se adotarmos o modelo centrado no fármaco, é possível explicar a ação dessa substância, já não a partir de um desequilíbrio restaurado, mas a partir da ideia de que o álcool provoca uma ligeira intoxicação, a qual nos faz sentir mais leves e alegres, menos inibidos ou tímidos, fatos esses que facilitam a interação social (MONCRIEFF, 2013a). Moncrieff, sintetiza esses dois modelos explicativos dos efeitos provocados pelos psicofármacos no quadro a seguir.

\section{Quadro I - Modelos de ação farmacológica}

\begin{tabular}{|c|c|}
\hline Modelo centrado na doença & Modelo centrado no fármaco \\
\hline $\begin{array}{l}\text { Os fármacos corrigem um estado anormal } \\
\text { do cérebro. }\end{array}$ & $\begin{array}{c}\text { Os fármacos criam um estado alterado } \\
\text { no cérebro. }\end{array}$ \\
\hline $\begin{array}{l}\text { Os efeitos benéficos dos fármacos derivam dos } \\
\text { efeitos sobre um suposto "processo de doença". }\end{array}$ & $\begin{array}{l}\text { Os efeitos induzidos pelos fármacos se } \\
\text { solapam, se alteram e se superpõem à } \\
\text { expressão dos problemas psiquiátricos }\end{array}$ \\
\hline Exemplo: a insulina na diabetes. & Exemplo: o álcool para a ansiedade social. \\
\hline
\end{tabular}

Fonte: Moncrieff (2013c).

No caso específico dos antipsicóticos, afirma-se que eles bloqueiam os receptores de neurotransmissores como a dopamina. Trata-se de um modelo epistemologicamente muito frágil. Para Moncrieff (2013a, p. 36): "[...] a teoria do déficit neuroquímico, que é a teoria mais difundida sobre 
as origens dos sintomas e distúrbios psiquiátricos tem, de fato, escassa base científica como fundamento".

A maior parte das explicaçóes existentes sobre a ação dos neurolépti$\cos ^{2}$ é construída a partir do modelo centrado na doença, criando hipóteses etiológicas, como a hipótese dopaminérgica, que serão replicadas com outras drogas e em outras patologias. De acordo com esse modelo, os neurolépticos teriam a função de neutralizar ou normalizar os efeitos do excesso de ativação da dopamina no cérebro.

Se, ao contrário, observarmos o modo como agem as drogas antipsicóticas, sem fazer referência a causas orgânicas desconhecidas, veremos que os neurolépticos têm a capacidade de reduzir os níveis de dopamina no cérebro, levando a um estado de deficiência que diminui a atividade motora e mental a um nível que, ainda que possa ser útil em quadros de psicose grave, também pode ser altamente prejudicial quando a droga se utiliza por longos períodos ou quando seu uso pode ser substituído por outras abordagens terapêuticas menos agressivas.

Quando se trata de casos de psicose ou esquizofrenia, a calma, o desinteresse e a apatia conseguidas com os neurolépticos, como a clorpromazina, nada têm a ver com o fato da suposta hiperatividade da dopamina como causadora da doença. De acordo a autores como Breggin $(1991,2008)$, Moncrieff $(2008,2013 a, 2015,2017)$ ou Whitaker (2010, 2015), dentre outros, os neurolépticos produzem um estado de deficiência de dopamina no cérebro que pode ser útil para controlar os sintomas graves da psicose, tais como excessivos movimentos involuntários, alucinaçóes etc. No entanto, essa eficácia, como já foi assinalado por Deniker e Deniker (BOURGUIGNON et al., 1956) no início das pesquisas com neurolépticos, chamados também antipsicóticos, tem um custo muito elevado: a apariçáo de sintomas próximos aos que sofrem as pessoas com doença de Parkinson, imobilidade, rigidez muscular, diminuição das capacidades mentais, assim como a aparição de movimentos involuntários característicos dessa doença.

2 Utilizamos aqui a denominação antipsicótico e neuroléptico como sinônimos. No início da psicofarmacologia todo medicamento indicado para psicose, particularmente esquizofrenia, era denominado neuroléptico. Hoje a denominação neuroléptico se utiliza fundamentalmente para referir-se aos antipsicóticos clássicos, típicos ou de primeira geração, que se diferenciam dos antipsicóticos atípicos ou de segunda geração, porque estes últimos possuem menos efeitos colaterais evidentes, como síndrome de Parkinson, que seus antecessores. 
Do mesmo modo que ocorre com os doentes de Parkinson, os neurolépticos reduzem os movimentos voluntários e a expressividade facial, além de reduzirem as respostas emocionais. "Experiências como tristeza e felicidade são menos intensas, e as pessoas medicadas com esses fármacos afirmam sentirem-se emocionalmente plenas, indiferentes e insensíveis" (MONCRIEFF, 2013a, p. 65). Todos esses efeitos foram descritos por Deniker e sua equipe, como fazendo parte dos efeitos inerentes à ação do fármaco já no ano 1956 (BOURGUIGNON et al., 1956).

Nesse marco explicativo, são ainda apropriados os estudos de Deniker (1987) centrados nos efeitos dos neurolépticos, pois a clorpromazina não deixou de ser prescrita nem mudou seu modo de ação. Podemos imaginar, assim, que o controle dos sintomas chamados positivos da psicose - tais como agitação, agressividade, pensamentos confusos e alucinações - pode estar diretamente associado à ação de um fármaco que reduz o movimento físico e o nível de consciência, que desacelera a atividade mental e adormece $o$ paciente, provocando uma sensação de indiferença em relação a seu entorno.

O certo é que a insistência no modelo hegemônico de explicação da ação dos psicofármacos, centrado na doença, obscurece e silencia essa dimensão dos neurolépticos que somente pode ser descoberta quando adotamos uma perspectiva centrada no fármaco. Isso pode levar a esquecer de que a ação dos neurolépticos está indissociavelmente vinculada à apatia, ao aplanamento emocional e à redução das capacidades mentais, na medida em que eles "[...] agem como uma camisa de força com efeitos sobre a conduta e os processos mentais" (MONCRIEFF, 2013a, p. 69), produzindo algo semelhante a uma "desativação tanto física como mental" (BREGGIN, 1991).

Considerando esses efeitos provocados pelos antipsicóticos, proponho analisar de que modo, ao longo desta história que se inicia e 1954, a indústria farmacêutica divulgou a suposta eficácia terapêutica dos neurolépticos, particularmente da clorpromazina.

\section{$2 \mathrm{~A}$ indústria farmacêutica $\mathrm{e}$ a insistência no modelo centrado na doença}

O crescente interesse dedicado à clorpromazina como momento inaugural da psicofarmacologia, não só se evidencia na realização de congressos, pesquisas e publicaçóes acadêmicas e médicas. Como já foi 
analisado por Robert Whitaker (2010), a partir de 1954 a droga começou a receber grande atenção por parte da mídia. No dia 26 de março daquele ano, a FDA a aprovou para uso nos Estados Unidos. Imediatamente, o laboratório Smith, Kline \& French iniciou uma imensa campanha publicitária do Thorazine (nome comercial da clorpromazina nos EUA), que abrangia shows de tevê, publicidade gráfica e a publicação de artigos destinados ao público em geral em impressos de grande circulação como o The New York Times ou a revista Time. O primeiro artigo publicado sobre a clorpromazina apareceu na Revista Time em 1954. Sob o título "Uma droga maravilhosa em 1954", o texto relata a experiência do Dr. Charles Wesler Scull, do laboratório Smith, Kline \& French, que afirma que, depois de algumas doses, os pacientes que antes eram violentos se mantêm "calmos nas suas camas". Ainda que ele reconheça que a clorpromazina não representa uma cura para a doença mental, considera que seu valor está em permitir que os pacientes relaxem, tornando-os mais acessíveis a outros tratamentos (WHITAKER, 2010).

Em 1955, começaram a aparecer artigos no The New Tork Times. Vale destacar que, só nesse ano, foram publicados 11 artigos dedicados ao Thorazine (WHITAKER, 2010). Apenas alguns poucos artigos manifestavam certa preocupação em relação aos efeitos da droga, enquanto outros elogiavam a ação tranquilizante que ela provocava nos pacientes e o fato de ter mudando a rotina dos hospitais psiquiátricos. Um artigo ,publicado em 19 de abril no The New York Times, adota uma posição mais cautelosa; refere-se aos problemas causados pela droga desta forma: "Drogas da serenidade preocupam os médicos: os efeitos secundários no tratamento dos transtornos mentais" (SERENITY, 1955, p. 19). Na verdade, esse texto se refere aos efeitos colaterais da reserpina, afirmando que essa droga poderia produzir depressão. Porém, em relação à clorpromazina, afirma-se que ela representa um grande progresso, porque permite reduzir o número de tratamentos com eletrochoques. $\mathrm{O}$ artigo agrupa essas drogas com o nome de "ataráxicos", que "vem do grego, ataraxia, que significa liberdade da confusão ou paz da mente. Foi utilizado também para significar serenidade aumentada” (SERENITY, 1955).

O modelo centrado na doença (MONCRIEFF; COHEN, 2005) parece ser a referência privilegiada para entender a ação dos fármacos desde o 
início das publicações destinadas ao grande público. Isso fica particularmente claro nos textos de um divulgador da ação terapêutica da clorpromazina chamado Robert Plumb. Um de seus artigos, publicado em 07 de outubro de 1955, diz que a clorpromazina possibilitou o retorno de pacientes a seus domicílios, reduzindo o uso de contençóes mecânicas e o isolamento nos hospitais em 50\%, o que permitiria a recuperação em casos de psicose (PLUMB, 1955b). O mesmo autor escreveu outro artigo nesse mesmo ano, "Novas drogas acalmam mentes perturbadas", em que expôs o que os médicos falam sobre o tratamento da esquizofrenia com as novas drogas.

Com o uso desses materiais, disse Fabing, cerca de seis entre dez casos iniciais de esquizofrenia podem ser tratados. Os compostos têm outros efeitos estranhos, observou ele. Alucinações, por exemplo, que afligem pacientes particularmente idosos, podem ser aliviadas. (PLUMB, 1955a).

Porém, a referência privilegiada é dada pela calma que a droga permite conquistar nas salas dos hospitais psiquiátricos. Um ano mais tarde, em 1956, o mesmo autor escreve no The New York Times (NEW, 1956) o artigo "Salas tranquilas mostram a ajuda das drogas" (PLUMB, 1956). O texto conta que a chegada da clorpromazina e da reserpina ao Hospital de Rochester, em somente um ano, transformou completamente as salas do hospital. As barras de ferro desapareceram, as paredes estáo limpas, os pacientem agora podem ter espelhos e se importam com a própria aparência, caminham pelos parques e escutam rádio e televisão. Os homens aprenderam ofícios de carpinteiro e pedreiros, os mesmos que, um ano antes, não podiam ter uma faca por perto porque podiam ferir a si ou aos outros. $\mathrm{O}$ artigo continua com a descrição de um verdadeiro oásis de calma no interior do manicômio, acrescentando que "[...] os pacientes não estão curados, mas alguns voltam a ter a esperança de poder sair da instituição” (PLUMB, 1956).

A calma no interior do hospital e a possibilidade de obter alta, mesmo com a continuidade da terapia em domicílio, era o tópico mais recorrente nos textos publicados nesse período, ainda que os efeitos colaterais graves decorrentes do consumo da droga não pudessem ser completamente negados ou silenciados. Esse fato era divulgado também pela publicidade, na qual a indústria farmacêutica investiu de modo constante a partir da aparição do Thorazine. 
Em 1956, o laboratório Smith, Klein \& French (SK\&F), publicitava a grande conquista da droga e a tranquilidade das salas dos hospitais com este anúncio:

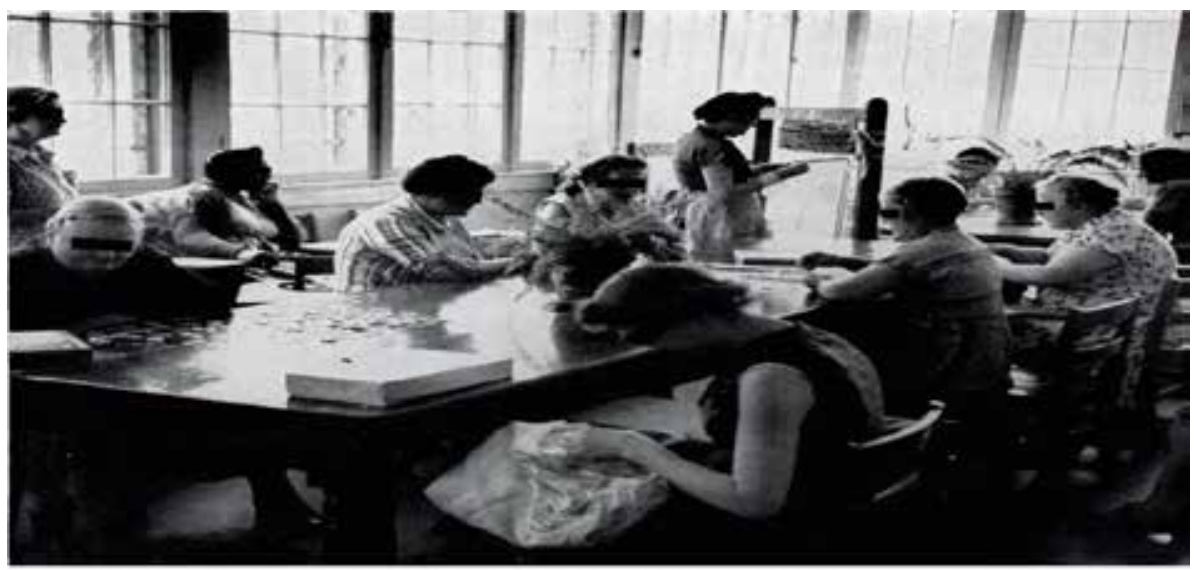

"alstuxbed vorda have virtually disappeaxed".

Many hompitats thave foused that

THORA乙INE*

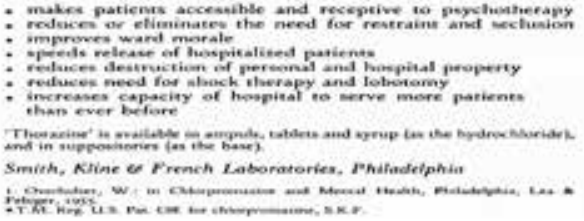

Figura I - Publicidade de Thorazine. Smith, Kline E French ( 1956)

Fonte: Procon (2020).

As salas complicadas e barulhentas foram substituídas, após o uso desse fármaco, por salas calmas e tranquilas. A publicidade informa que foi reduzida a necessidade de reclusão, de eletrochoques e lobotomia, que a droga evita a destruição de bens e materiais, aumenta a moral dos pacientes e, fundamentalmente, acelera a saída destes dos hospitais. Isto é, permite que eles se insiram nessa nova modalidade terapêutica que entáo se inicia e que pode ser defina como tratamento contínuo. Por esse motivo, o laboratório SK\&F também investirá na divulgação de Thorazine para tratamento extra-hospitalar. 


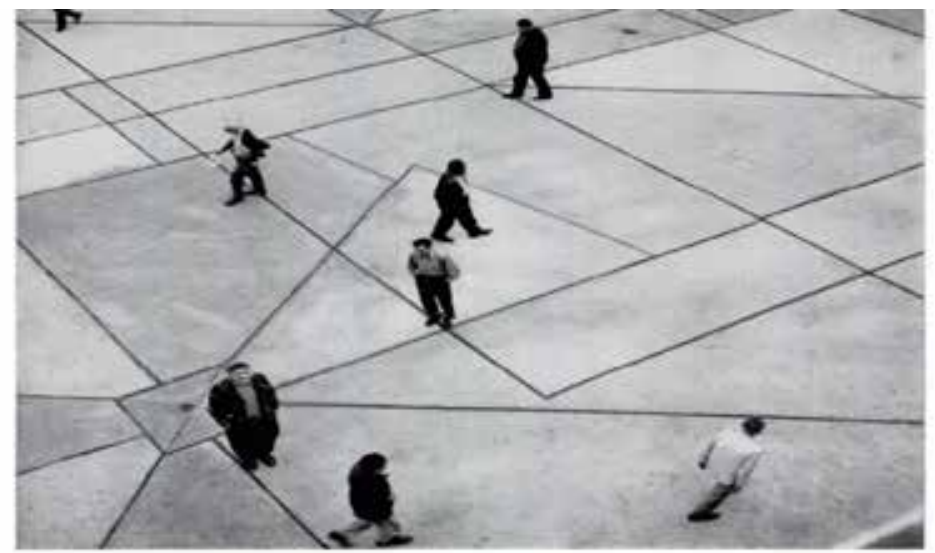

THORAZINE*

helps to keep more patients out of mental hospitals

\begin{abstract}
With "Thorazine' "more patients will be released after shorter periods of hospitalization and fewer patients will require re-hospitalization. More patients can be treated in the community, at clinics or in the psychiatrist's office without being hospitalized at all."'
\end{abstract}

'Themasine' is avsilable as the hydrochloride in ampuls, tablets and syrupi and as the base in suppositories.

For information wrie: Smith. Nline \& French Laboratories, 15 30 Spring Garden Street, Phila.t

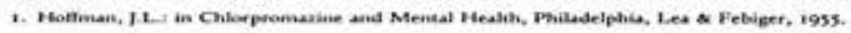

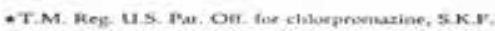

Figura 2 - Publicidade de Thorazine. Smith, Kline E French (1955) Fonte: Procon (2020).

No anúncio publicitário de 1955 (Figura 2), podemos observar a divulgação da terapia contínua com clorpromazina. Do mesmo modo que aparece em artigos científicos, nos trabalhos de Deniker (1987) ou nos artigos de divulgação massiva, a propaganda do laboratório destaca que mais pacientes podem sair do hospital. Os pacientes terão tratamentos com internaçóes mais breves, e poucos deles irão precisar de re-hospitalizaçáo, acrescentando-se que os pacientes podem ser tratados com Thorazine fora do hospital, em centros de saúde mental ou consultórios psiquiátricos.

Nesse mesmo ano, aparece no The New York Times um artigo titulado "Novo medicamento tranquilizante: 550 pacientes se acalmaram com a clorpromazina. Não se observaram interações secundárias no teste” (NYT, 1956, p. 25); contradizendo seu próprio título, o texto informa que: 
A clorpromazina às vezes pode causar efeitos, como uma queda abrupta da pressão arterial, icterícia, aceleração do coração, redução de glóbulos brancos e uma afecção que se assemeIha a uma paralisia com tremores. Além disso, há dor no local onde se realizou a injeção e irritação da pele quando se administra clorpromazina injetável. (NYT, 1956, p. 25).

De fato, a forma mais simples que a indústria farmacêutica tinha para tornar aceitáveis esses efeitos colaterais e para garantir o retorno dos investimentos realizados em pesquisa era recorrer ao modelo de ação do fármaco centrado na doença. Sem esse recurso, seria impossível divulgar e vender os psicofármacos. Assim, ainda que a clorpromazina seja amplamente divulgada para médicos e pacientes em geral como uma droga ataráxica, que permite a conquista da tranquilidade tão desejada nos hospitais psiquiátricos, sempre aparecerá associada a um efeito terapêutico. Afirmava-se que as pessoas mais calmas atingiriam mais facilmente a cura ou a reversáo dos sintomas. E quando isso não ocorria pela ação direta da droga sobre o Sistema Nervoso Central, afirmava-se que a calma conquistada permitiria iniciar outras terapêuticas, como a psicanálise, reduzindo o número de eletrochoques e de outras terapias violentas.

A divulgação do efeito terapêutico da clorpromazina foi indispensável para que uma droga cuja ação principal é docilizar os pacientes e que possui efeitos colaterais dramáticos pudesse ser aceita como um modelo a ser replicado em futuras descobertas. Se observarmos o modo como o Thorazine era divulgado entre 1954 e 1959, veremos que, de acordo com o laboratório SK\&F, uma diversidade de problemas psiquiátricos e mentais podiam ser tratados com esse psicofármaco: esquizofrenia, ataques de mania, tristeza profunda, problemas emocionais da menopausa, assim como casos de alcoolismo agudo. Do mesmo modo, como veremos aqui, afirmava-se que a Thorazine podia ser muito útil para o tratamento de transtornos da infância.

Vemos, assim, que as primeiras publicidades de Thorazine, as quais apareceram em 1955, apresentam a droga como terapêutica na cura da esquizofrenia e da mania, como pode ser observado nestas publicidades, ambas do mesmo ano: 


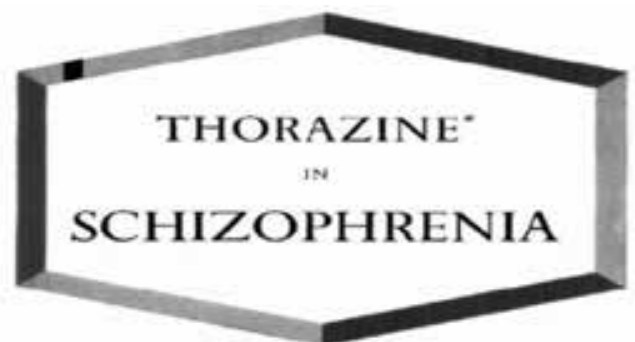

"Our mose eacouraging results have occurred in chronic

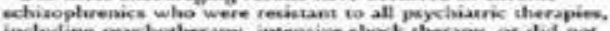
including paychotherapy, intensive shock therapy, or did not maintain inperoveneent after prefroesal lobotomy, Afier they were placed on the 'Thoraxine' program, 17 of the 37 , oe 635 of the shoch treatmecot failures improved vafficienaly to be discliarged houne:"

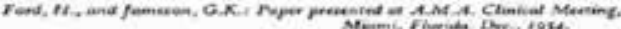

'Thmonnine' Hydrochloride is available in wo mg, 25 mg, 50 mg

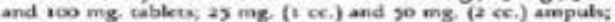
and syrup (10 $\mathrm{mg} / \mathrm{s} \mathrm{ce}$.)

Addiskonal information on 'Thorsaine' is available on requese.

Smith, Kline \& French Laboratories

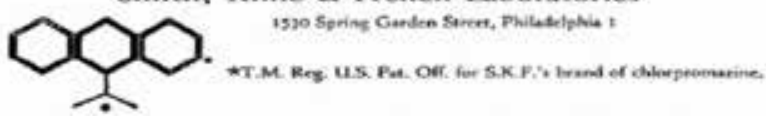

\section{THORAZINE*}

to control

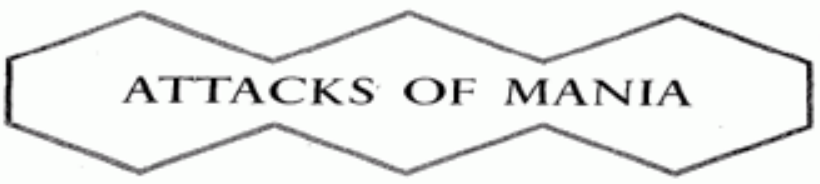

On administration of "Thorazine", "attacks of mania with accompanying elation, overactivity and delusions of grandeur subside rather promptly... This alone represents a therapeutic advance since mania often resises shock therapies and is a very exhausting condition for the patient, relatives and hospital staff." Kinrass-Wright, V.; Postgrad. Med, 16:297 (Oct,) 1954. Available in $10 \mathrm{mg} ., 25 \mathrm{mg} ., 50 \mathrm{mg}$, and $100 \mathrm{mg}$. tablets; $25 \mathrm{mg}$. (1 ce.) ampuls and $50 \mathrm{mg}$. (2 ce.) ampuls.

Information on "Thorazine" is available on request.

Smith, Kline \& French Laboratories

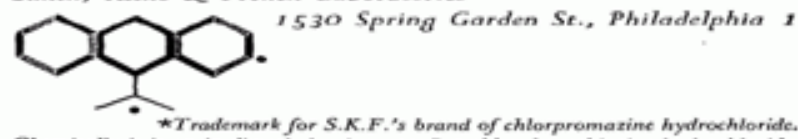

Chemically it is 10-(3-dimethylaminopropyl)-2-chlorphenothiazine hydrochloride.

Figura 3 - Publicidade de Thorazine. Smith, Kline \& French (1956)

Fonte: Procon (2020). 
Um ano mais tarde, em 1956, os usos se ampliam para outros transtornos, tais como o alcoolismo e a tristeza profunda, como mostram as publicidades de Thorazine a seguir:
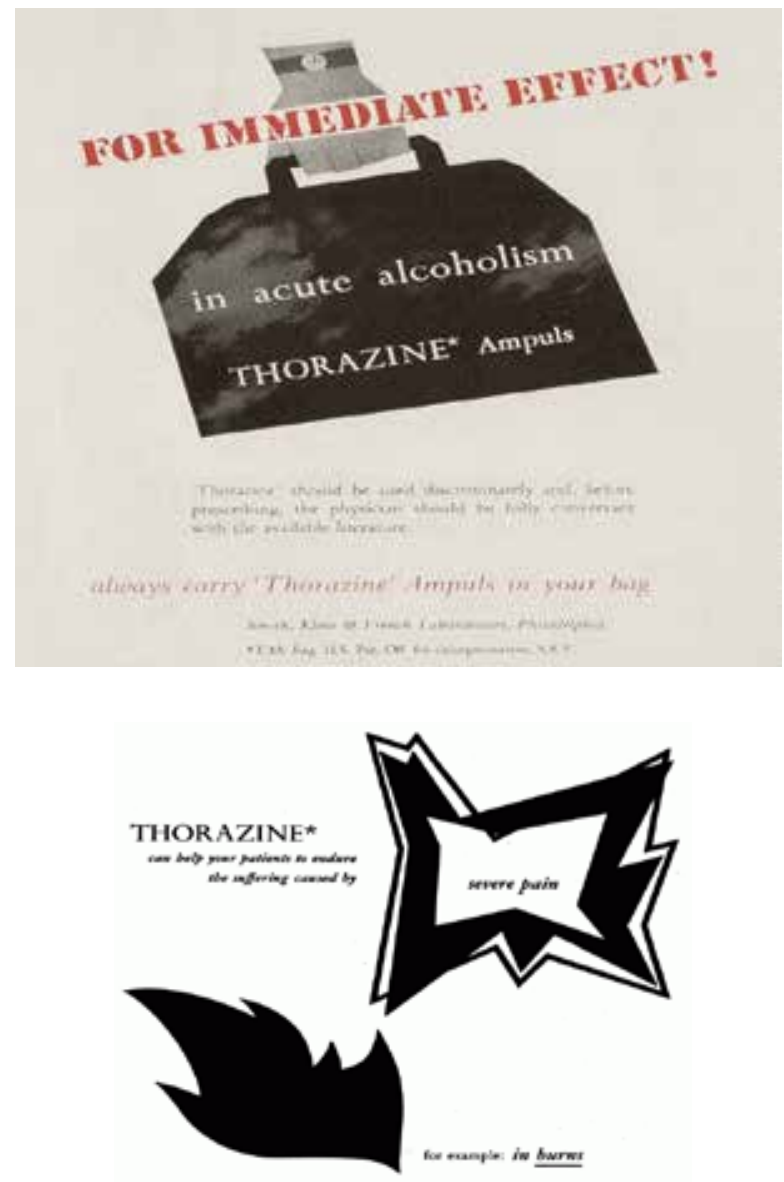

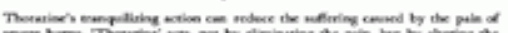

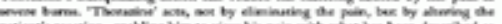

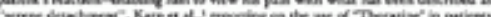

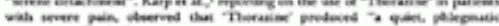

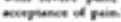

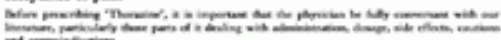

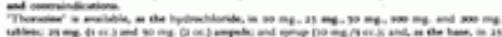

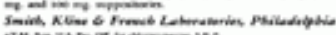

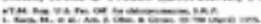

Figuras 4 e 5 - Publicidade de Thorazine. Smith, Kline E French (1955) Fonte: Procon (2020). 
Podemos descobrir aqui o momento preciso no qual se inicia esse processo de farmacologização da vida cotidiana que se consolidará mais tarde, nas últimas décadas do século XX, a partir da maciça generalizaçáo de psicofármacos como o Prozac. A partir do momento em que a clorpromazina pôde ser prescrita para pacientes que já saíram do hospital psiquiátrico, abriu-se a possibilidade de ampliar o campo de ação dos psicofármacos. Os neurolépticos, além de ser utilizados para as psicoses graves que exigem internação hospitalar, puderam ser prescritos para tratar os sofrimentos cotidianos e os comportamentos considerados desviados ou fora da norma. Um processo que se consolidou com a redefinição e ampliação de diagnósticos psiquiátricos a partir de agrupamentos de sintomas, iniciadas em 1980 com o DSM-III.

Já em 1957 podemos encontrar no The New York Times um bom exemplo dessa tendência à farmacologização da vida cotidiana no artigo denominado "Altos e baixos com pílulas: estimulantes e tranquilizantes agora vendidos em grandes quantidades para o público" (UPS, 1957). $\mathrm{O}$ texto se refere à preocupação da American Psychiatric Association (APA) com o uso crescente de pílulas para animar as pessoas associado a outras pílulas para baixar o ânimo. Náo sem ironia, o artigo avalia o imenso crescimento de prescriçóes tanto de excitantes, como as anfetaminas, como de tranquilizantes maiores, como a clorpromazina.

A indústria farmacêutica estima que em 1957 um total de 40 milhões de prescrições serão escritas para as novas drogas ataráxicas. Não há uma boa estimativa do número total de pílulas tranquilizantes que 40 milhões de prescrições representam: cada prescrição pode ser preenchida muitas vezes e dividida com amigos, parentes, talvez até mesmo para ser introduzida na ração do cão da família. (UPS, 1957).

$\mathrm{O}$ artigo acrescenta que, quando se observa a imensa quantidade de prescriçóes, parece que as pessoas acreditam que as anfetaminas e os tranquilizantes maiores carecem de efeitos adversos. Afirma também que essas drogas não agem sobre a causa da patologia, limitando-se a controlar sintomas socialmente indesejados, um fato que também parece ser desconhecido dos pacientes. Certamente, a publicidade do laboratório SK\&F teve um forte impacto, tanto no aumento do número de prescriçóes, como no desconhecimento dos efeitos adversos por parte da população, pois esses efeitos eram sistematicamente ocultados. A publicidade de Thorazine evidencia o interesse de inserir no mercado, além das mulheres depressivas, fatigadas ou nervosas, os dois extremos mais vulneráveis da população: a infância e os idosos. 


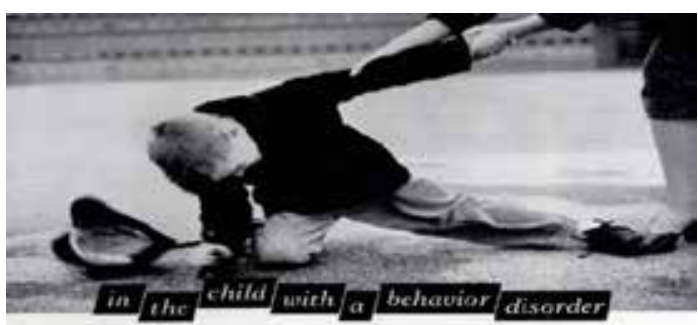

\section{THORAZINE*}

redieces hyperractivity and segressiveress

decreases anviery and hoseiliry

improoes mood, behavior and sleeping habiss

establishes exressibility to gaidance or psychatheropy

inereates amenability to supereision
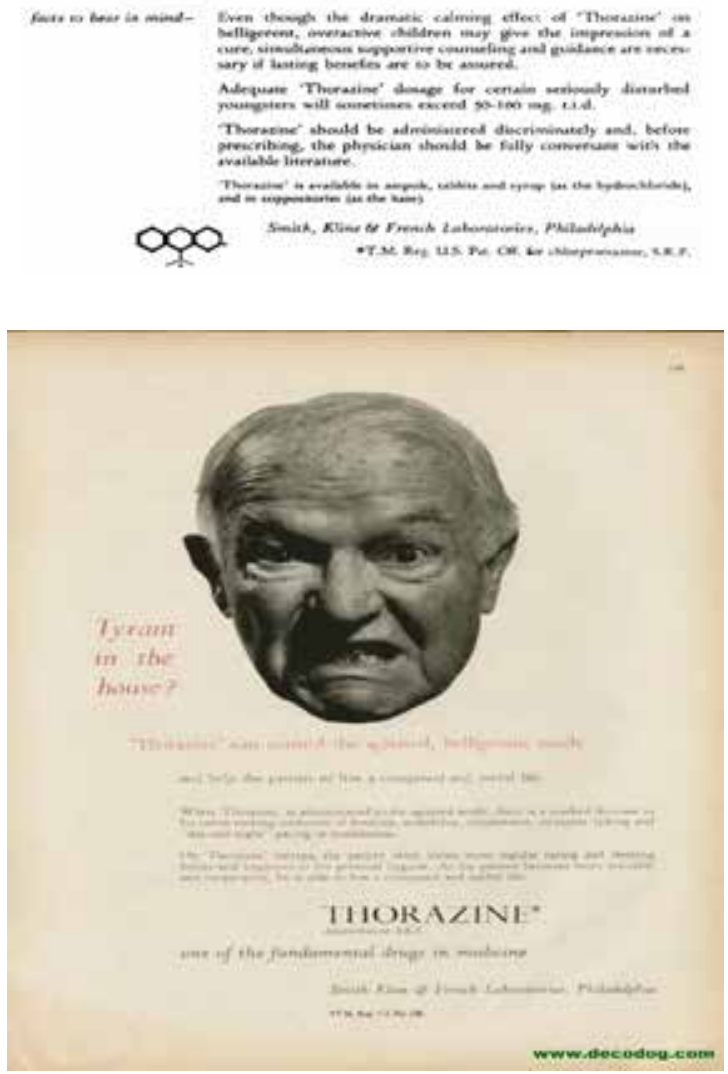

Figuras 6 e 7 - Publicidade de Thorazine. Smith, Kline E French (1956, 1959)

Fonte: Procon (2020). 
Nesses dois casos, o Thorazine é publicitado como um fármaco cuja utilidade é menos terapêutica que de controle e normalizaçấo de comportamentos. No primeiro caso, a publicidade de 1956 se refere ao uso da medicação para problemas de comportamento na infância, atribuindo-lhe a capacidade de reduzir a hiperatividade, a ansiedade, melhorar os hábitos de sono, assim como aumentar a receptividade para a supervisão, isto é, fazer das crianças sujeitos disciplinados e governáveis. No segundo caso, a publicidade é de 1959, e se refere ao auxílio que o Thorazine presta para gerir os comportamentos indesejados dos idosos, tais como agressividade, beligerância, falar muito, não obedecer aos cuidadores. Assim, do mesmo modo que ocorre em relação às crianças, os comportamentos indesejados das pessoas idosas poderão ser melhor administrados com Thorazine.

Ainda que Delay e Deniker tivessem excluído explicitamente algumas doenças, afirmando que transtornos como a depressão não poderiam ser tratados com a clorpromazina (DENIKER, 1987), pouco a pouco se somaram mais e mais patologias à lista de doenças que podiam ser curadas com essa droga, a tal ponto que, em 1968, a publicidade do Thorazine pôde incluir um "formidável" conjunto de padecimentos, capazes de cobrir completamente as letras do alfabeto.

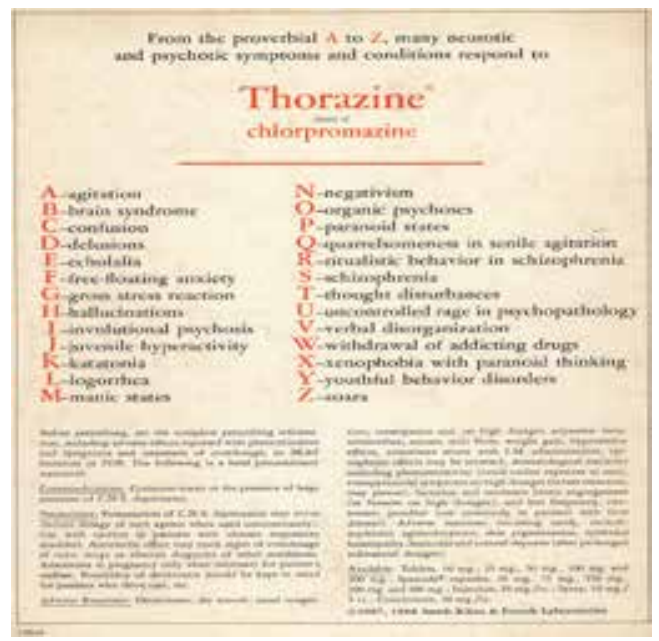

Figura 8 - Publicidade de Thorazine. Smith, Kline \& French (1968). Fonte: Procon (2020). 
Na Figura 8, podemos observar que o anúncio publicitário de 1968 que, 15 anos após a descoberta da clorpromazina para o controle dos sintomas de psicoses o laboratório Smith, Kline \& French divulga o uso da medicação para uma imensa variedade de patologias, padecimentos e comportamentos indesejados. Todas as letras do alfabeto podem ser tratadas com clorpromazina, desde a confusão, a esquizofrenia e as alucinaçóes, até os estados maníacos, a paranoia, a raiva incontrolável, os comportamentos indesejados nos jovens, o negativismo, a xenofobia etc.

Temos ali um excelente exemplo de até que ponto a indústria farmacêutica transforma em funcional o desconhecimento dos mecanismos de ação da droga, o "como" ela atua. De fato, o único conhecimento que se repete até o cansaço é a capacidade tranquilizadora e sedativa da droga, sua função ataráxica, extremamente útil para gerir comportamentos agitados, violentos ou considerados inadequados. Para sustentar essa rede de saber- poder e, ao mesmo tempo, silenciar os efeitos adversos da droga, o modelo de ação dos fármacos centrado na doença resulta iniludível. O que os artigos científicos, os artigos de divulgaçáo publicados no The New York Times e a publicidade de Thorazine dessa primeira década da psicofarmacologia nos permitem concluir é que os dois modelos apresentados por Moncrieff para explicar a ação dos psicofármacos, o modelo centrado na droga e o modelo centrado na doença, aparecem sobrepostos e com contornos dúbios, desde o início da história da psicofarmacologia.

\section{Antipsicóticos e psicofarmacologização da infância}

Esses dois modelos se superpóem também quando falamos de psiquiatrização da infância, mas particularmente quando analisamos as respostas farmacológicas dadas a supostas doenças psiquiátricas vinculadas a comportamentos não desejados. Meu interesse aqui é apresentar de que modo a indústria farmacêutica apresenta o uso de antipsicóticos e particularmente o uso de antipsicóticos atípicos no domínio da infância. Como afirma Pignarre (2006), todo o esforço que a indústria farmacêutica dedicou, nos últimos 50 anos, aos psicofármacos em geral e aos antipsicóticos em particular, parece reduzir-se a achar um medicamento com menos efeitos colaterais que o medicamento existente no mercado, o que não significa que eles sejam terapeuticamente mais efetivos ou menos nocivos que os velhos antipsicóticos descobertos nos anos 1950, como a clorpromazina. Diversos estudos indicam que o uso de risperidona está associado a vários 
efeitos adversos, tais como: ganho de peso, hiperprolactinemia, sonolência, ansiedade, náuseas, tontura, boca seca, tremores, insônia, parkinsonismo, vômitos, tosse, constipação, dor abdominal, dor de cabeça e erupção cutânea (GALARCE, 2008; TCHEREMISSINE; LIEVING, 2006).

Quando olhamos para os antipsicóticos autorizados no Brasil para uso pediátrico, podemos observar que, de acordo a Agência Nacional de Vigilância Sanitária (ANVISA), existe autorização para uso pediátrico de dois antipsicóticos típicos, ou de primeira geração, a clorpromazina e o haloperidol, e de dois antipsicóticos atípicos, ou de segunda geração, eles são risperidona e quetiapina. Tal e como podemos observar no Quadro 2 , temos na primeira coluna da tabela a indicação do princípio ativo da droga, a marca, o fabricante e de que modo essa droga se apresenta, por exemplo: $25 \mathrm{mg}$. Uma segunda coluna explicita as indicaçóes presentes na bula, aparecem aqui misturados os nomes das patologias que essa droga trata, junto â descriçáo de atitudes ou comportamentos não desejados. Por fim, na terceira tabela aparece a indicação Uso na faixa pediátrica.

Para nossa surpresa, e apesar de tudo o que já se conhece sobre a clorpromazina, de terem sido divulgados todos os efeitos adversos dessa droga ao longo de 70 anos, a clorpromazina, particularmente a marca Amplictil, do Laboratório Sanofi-Aventis, é indicada para uso na faixa pediátrica, com o seguinte comentário: "uso adulto e pediátrico, dependendo da indicação". A prescrição de antipsicóticos não é exclusiva do campo da psiquiatria, também vemos repetir-se a mesma lógica na pediatria e medicina geral, seja para tratamento de crianças e jovens no pronto-socorro ou no consultório (MAGALHÃES BRAGA, 2011).

Esta droga continua divulgando-se, ainda hoje, de acordo ao modelo centrado na doença, sendo indicada em diferentes âmbitos: na neuropsiquiatria, indica-se para quadros psicóticos agudos e controle de psicoses de longa duração; na clínica geral, para manifestaçóes de ansiedade e agitação, soluços, náuseas e vômitos e para neurotoxicoses infantis. Vemos a repetição da mesma lógica aplicada em 1954, quando a clorpromazina era utilizada para um amplo espectro de patologias, podia ser um antiemético ou antivomitivo, um antipsicótico ou um tratamento para agitação. Podemos observar que hoje permanecem as mesmas indicaçóes ambíguas referentes a doenças orgânicas e psiquiátricas, ainda que seja muito bem conhecido que a verdadeira eficácia está na capacidade sedativa, calmante da droga, 
em sua capacidade de provocar indiferença e aplanamento emocional. Mas ainda hoje, assim como em 1956, sabemos que permanecem os mesmos efeitos colaterais identificados quando a clorpromazina foi descoberta. Sabemos que provoca (1) acatasia, isto é, transtornos do movimento e agitação psicomotora; (2) distonia, isto é, movimentos involuntários e contraçóes musculares e (3) discinesia tardia, sintomas semelhantes à doença de Parkinson, além de outras alteraçôes.

\begin{tabular}{|c|c|c|}
\hline $\begin{array}{l}\text { Drincipio ative } \\
\text { Marco/fabricante (roforência) } \\
\text { Apresentapōes }\end{array}$ & Indicapbes presentes em bula brasileira & $\begin{array}{l}\text { Uso na faica } \\
\text { pedibtrica }\end{array}$ \\
\hline \multicolumn{3}{|l|}{ Antipsicoticos ot ipicos } \\
\hline 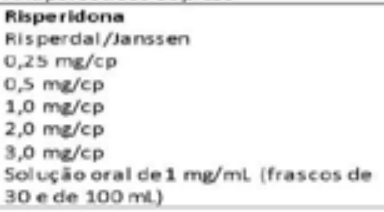 & $\begin{array}{l}\text { Esquizofrenia; a gita,z̃o, a gressividadeousintomas psicóticos } \\
\text { em pacientes com demencia do tipo Al zheimer; mania no } \\
\text { transtorno afetivo bi polar; autisme. }\end{array}$ & $\begin{array}{l}\text { Uso adulto e } \\
\text { pediatrico, } \\
\text { dependendo da } \\
\text { indica ça.o. }\end{array}$ \\
\hline $\begin{array}{l}\text { Quetiapina } \\
\text { Sercquel/Astrazeneca } \\
25 \mathrm{mg} / \mathrm{cp} \\
100 \mathrm{mg} / \mathrm{cp} \\
200 \mathrm{mg} / \mathrm{cp} \\
300 \mathrm{mg} / \mathrm{cp}\end{array}$ & 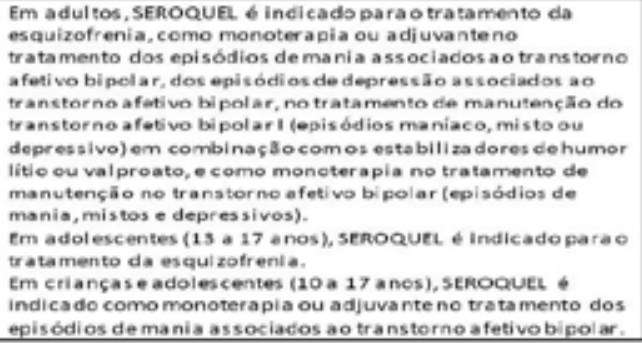 & $\begin{array}{l}\text { Uso adulto } \\
\text { pediátrico, } \\
\text { dependendo da } \\
\text { indica cto. }\end{array}$ \\
\hline \multicolumn{3}{|l|}{ Antipsicóticos tipicos } \\
\hline $\begin{array}{l}\text { Clorpromaxina } \\
\text { Amplictil/Sanofi-Aventis } \\
25 \mathrm{mg} / \mathrm{cp} \\
100 \mathrm{mg} / \mathrm{cp}\end{array}$ & 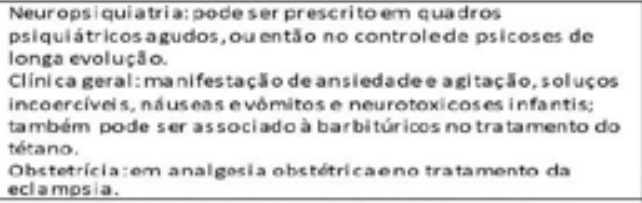 & $\begin{array}{l}\text { Uso a dultoe } \\
\text { pedístrico, } \\
\text { dependendo da } \\
\text { indicacJo. }\end{array}$ \\
\hline $\begin{array}{l}\text { Haloperidol } \\
\text { Haldol/Janssen } \\
1 \mathrm{me} / \mathrm{cp} \\
5 \mathrm{mg} / \mathrm{cp}\end{array}$ & 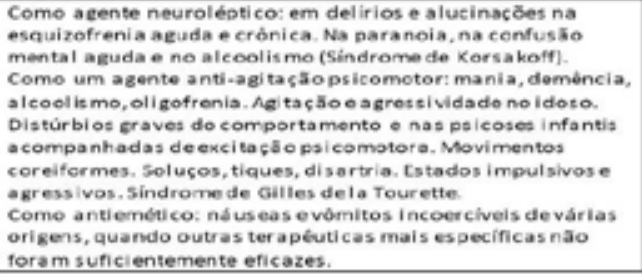 & $\begin{array}{l}\text { Uso adulto e } \\
\text { pedistrico. } \\
\text { dependendo da } \\
\text { indicasto. }\end{array}$ \\
\hline
\end{tabular}

Quadro 2 - Indicação de antipsicóticos para uso pediátrico extraída da tabela geral adulto/pediátrico

Fonte: Adaptado de Anvisa (20/4). 
Quando observamos a Bula da medicação Amplictil (ANVISA, 2018), aprovada pela ANVISA, encontramos que o medicamento é utilizado para o tratamento de um imenso conjunto de patologias, esclarecendo que, à medida que tem como princípio ativo a clorpromazina, se trata de um medicamento que age no Sistema Nervoso Central e é muito útil para controlar diversos tipos de excitação, perturbaçôes mentais e emocionais. Falamos anteriormente sobre o uso da droga em adultos e mencionamos seu uso em crianças nas décadas de 1950 e 1960, quando ainda não eram tão conhecidos os efeitos da droga; mas, hoje, apesar de todo o conhecimento que temos sobre o efeito devastador da droga, o Amplictil é aprovado para uso pediátrico, a partir dos dois anos de idade.

Uso em crianças (acima de $\mathbf{2}$ anos) Deve-se usar o mesmo esquema já citado de aumento gradativo de dose, sendo usualmente utilizada uma dose inicial de $1 \mathrm{mg} / \mathrm{kg} / \mathrm{dia}$, dividida em 2 ou 3 tomadas. O total da dose diária não deve exceder $40 \mathrm{mg}$, em crianças abaixo de 5 anos, ou $75 \mathrm{mg}$, em crianças mais velhas. (ANVISA, 2018).

Observamos que as mesmas 40 mg que Delay e Deniker (1952) preconizavam como dose máxima para pacientes adultos psicóticos internados em asilos são indicadas hoje para crianças de 2 a 4 anos. Existe um único modo de legitimar essa prescrição, afirmando que esse medicamento é necessário para curar uma doença mental existente ou para restabelecer o equilíbrio perdido no sistema cerebral da criança. Dir-se-á, então, que o Amplictil serve para tratamento de transtornos mentais como psicose, e para tratamento de problemas orgânicos vários (náuseas, agitação, soluços), ainda que a explicação para essa ação terapêutica do medicamento fique vaga, ambígua e duvidosa, limitando-se a afirmar que a droga age no Sistema Nervoso Central: "Amplictil tem como princípio ativo a clorpromazina, que é um medicamento que age no sistema nervoso central controlando os mais variados tipos de excitação. É, portanto, de grande valor no tratamento das perturbaçôes mentais e emocionais" (ANVISA, 2018, [s. p.]).

A ampla variedade de usos possíveis para a droga, e a referência concreta ao controle de diversos tipos de excitação, parece indicar que não existe nenhuma relação terapêutica entre esta droga e uma patologia determinada. No entanto o modelo de explicação do fármaco centrado na doença 
continua. A funcionalidade desse modelo parece evidente si nos perguntamos porque motivo crianças de 2 a 5 anos, ou maiores de 5 anos, poderiam vir a ser tratadas com clorpromazina. Não parece ser razoável hoje tratar crianças com soluço ou vômitos com antipsicóticos, mas também não parece ser razoável, nos dias de hoje, medicar uma criança na primeiríssima infância com antipsicóticos aduzindo a existência de um suposto transtorno mental grave e desconsiderando as consequências implicadas. Isto é, continuar repetindo a mesma lógica que a indústria farmacêutica impunha na publicidade de Thorazine nos anos 1950.
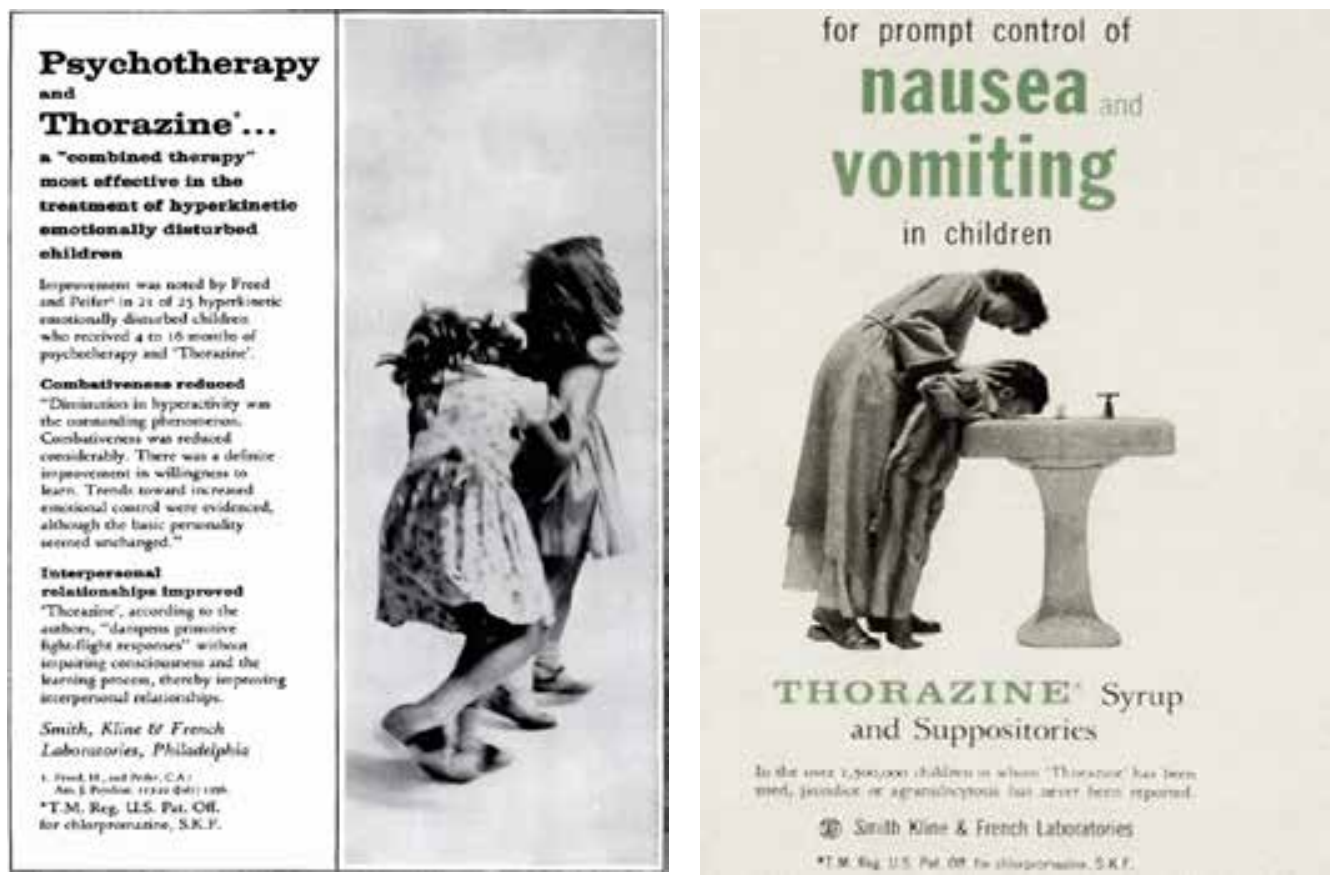

Figura 8 - Publicidade de Thorazine. Smith, Kline E French (1956, 1969).

Fonte: Procon (2020).

Se, pelo contrário, observamos o fármaco a partir do modelo centrado na droga várias perguntas e respostas podem surgir. Quando se reconhece que o efeito desejado da droga é, como já foi dito, a conquista da calma, a 
ataraxia, o aplanamento emocional, deveremos observar qual é o impacto real que a droga provoca no Sistema Nervoso Central e deveremos considerar que os efeitos adversos produzidos estáo inevitavelmente associados à ação da droga no Sistema Nervoso Central, desde os sintomas de Parkinson até a morte súbita.

Dir-se-á que, de fato, este é um medicamento pouco utilizado em pediatria e neuropediatria, porque seus efeitos colaterais já são bem conhecidos. Também que os antipsicóticos clássicos ou típicos, como o Amplictil foram substituídos por novos antipsicóticos, de última geração, chamados antipsicóticos atípicos. No entanto, de acordo aos trabalhos realizados por Gotszche (2016), Whitaker (2017), Moncrieff (2017), dentre outros, tudo parece indicar que o efeito dos antipsicóticos atípicos também produz severos danos no organismo de uma criança, danos que superam os benefícios alegados (GOTSZCHE, 2016).

Se os antipsicóticos clássicos são pouco utilizados em crianças e adolescentes, não é isso o que ocorre com os antipsicóticos atípicos aprovados pela ANVISA para uso pediátrico. Esses antipsicóticos são: (1) risperidona, cuja marca comercial é Risperidal', do laboratório Janssen, indicado para esquizofrenia, agitação, agressividade, sintomas psicóticos, transtorno bipolar e autismo, e (2) quetiapina, cujo nome comercial é Seroquel ${ }^{\circ}$, do Laboratório Astrazeneca, indicado para transtorno bipolar, mania, depressão, esquizofrenia, recomendado para adolescentes de 13 a 17 anos, e para crianças e adolescentes de 10 a 17 anos, para tratamento de mania associado ao transtorno afetivo bipolar. Esses dois antipsicóticos produzem efeitos semelhantes: acalmar os pacientes, conter os episódios de mania e agressividade.

Do mesmo modo que a clorpromazina, o uso de antipsicóticos provoca efeitos colaterais extremamente graves, muitos dos quais também estão presentes nos antipsicóticos atípicos. Vimos que a clorpromazina se apresentava como "cura" para a esquizofrenia ou as psicoses, ou como um tratamento contínuo capaz de reverter a patologia, embora não existissem nem em 1954, nem hoje, explicaçóes sobre o mecanismo neuroquímico que provocaria a doença, mantendo-se as causas biológicas desconhecidas. Vimos que, quando se tratava de defender a eficácia da clorpromazina, já não se falava de cura, mas sim da capacidade de a droga conseguir a desejada calma nos pacientes psiquiátricos, 
a indiferença em relação ao que ocorria em seu entorno, a redução de sua agressividade e agitação. Isto é, a clorpromazina permitia transformar pacientes agitados em pacientes disciplinados e, paralelamente, transformar as salas dos pacientes agitados em salas tranquilas (CAPONI, 2019).

Os problemas apresentados em relaçáo à clorpromazina náo desaparecem com os antipsicóticos atípicos, ao contrário, medicamentos como a risperidona podem provocar graves efeitos colaterais, ainda mais se considerarmos o fato de que os antipsicóticos deixaram de ser prescritos exclusivamente para pacientes com patologias mentais graves, esquizofrenia ou psicoses, para se estenderem ao conjunto da sociedade, particularmente às crianças. Como veremos, a risperidona é prescrita com a finalidade de tratar pequenas faltas de conduta, comportamentos agressivos, hostilidade, desrespeito às autoridades, isto é, comportamentos que indicam um "denominador comum" para um conjunto de situaçôes adversas de vida que não podem ser desconsideradas, nem ocultadas por um psicofármaco cujo efeito desejado é provocar aceitação, obediência, docilidade, indiferença às adversidades, e, paralelamente, conquistar a desejada calma e tranquilidade nas salas de aula.

\section{Risperidona e o controle dos comportamentos na infância}

Gostaria de analisar aqui o uso de um desses antipsicóticos atípicos, a risperidona, no campo da infância, por ser uma medicação muito utilizada no Brasil e em outros países do mundo. Essa droga se indica para crianças com autismo, agitação, hiperatividade e também para crianças e adolescentes que recebem o diagnóstico de Transtorno opositor desafiante (TOD). Trata-se de um transtorno extremamente ambíguo, que, na verdade, faz referência a condutas socialmente indesejadas de crianças e adolescentes, tais como a não aceitação de autoridades e o comportamento hostil e desafiador. Esses comportamentos, que podem ser irritantes, incômodos e fatigantes, de fato não constituem sintomas de nenhuma patologia.

Para entender o surgimento desses antipsicóticos atípicos hoje amplamente usados para o autismo, as psicoses e o TOD, é importante entender que, ao longo dos anos 1980, cada vez eram maiores as críticas e os 
estudos que mostravam a pouca eficácia dos antipsicóticos clássicos, como a clorpromazina, para a cura, ou melhor, para o controle dos sintomas dos transtornos psiquiátricos como a esquizofrenia. Nesse contexto, antipsicóticos com menos efeitos colaterais que os anteriores apareciam como uma alternativa promissora diante das evidências de insucesso dos medicamentos clássicos. Assim, de acordo com Whitaker, ao longo dos anos 1980:

Os pesquisadores também começaram a admitir que os neurolépticos não controlavam ilusões e alucinações muito bem. Dois terços de todos os pacientes medicados apresentavam sintomas psicóticos persistentes um ano após o primeiro surto psicótico. Trinta por cento dos pacientes não responderam às drogas - uma taxa de "não resposta" que, até a década de 1980, quase nunca havia sido mencionada. Vários estudos sugeriram que mesmo esse número de $30 \%$ poderia ser muito baixo, e que até dois terços de todos os pacientes psicóticos poderiam ser considerados "não respondedores" aos neurolépticos. Talvez a confissão mais reveladora de todas tenha vindo dos cientistas do NIMH: "Nossa experiência clínica é que, embora a intensidade do distúrbio do pensamento possa diminuir com o tratamento medicamentoso, o perfil do distúrbio do pensamento não é alterado". (WHITAKER, 2010, p. 480).

Nesse contexto geral surgem os antipsicóticos atípicos, como uma forma de dar uma resposta aos efeitos indesejados dos antipsicóticos clássicos. Ainda que os debates acadêmicos e as pesquisas mostrassem o fracasso dos antipsicóticos como alternativa terapêutica, pondo em evidência que até $80 \%$ dos pacientes tratados ficava cronicamente desempregado e vivendo da ajuda do Estado, as informaçóes veiculadas para o grande público continuavam falando de sucesso terapêutico. Porém, como os efeitos colaterais graves provocados pelos neurolépticos tinham cada vez mais reconhecimento e eram cada vez mais divulgados, a soluçáo imediata da indústria farmacêutica foi afirmar que os efeitos adversos dessas drogas podiam ser controlados, com mais drogas. Tal como podemos observar nesta publicidade em que Cogentil ${ }^{\circ}$, uma droga utilizada até hoje, é apresentada como a solução para controlar os três sintomas extrapiramidais do Thorazine: acatisia, distonia e acinesia. 


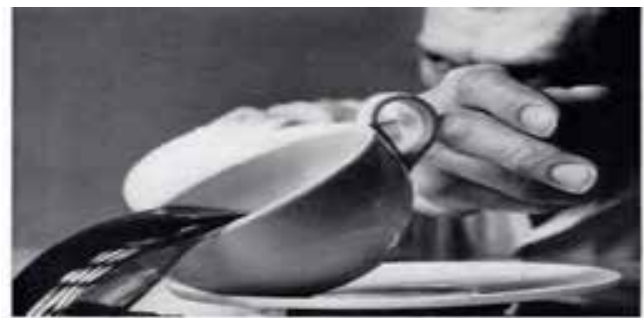

to control tranquilizer-induced Parkinson-like side effects

\section{BOGENTIN.}

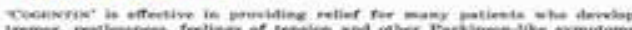

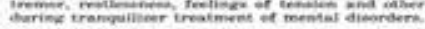

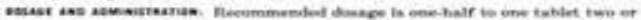

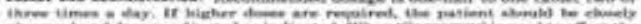

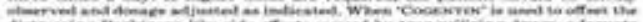

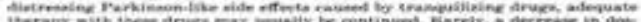
tore miny is newwern

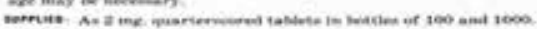

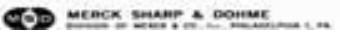

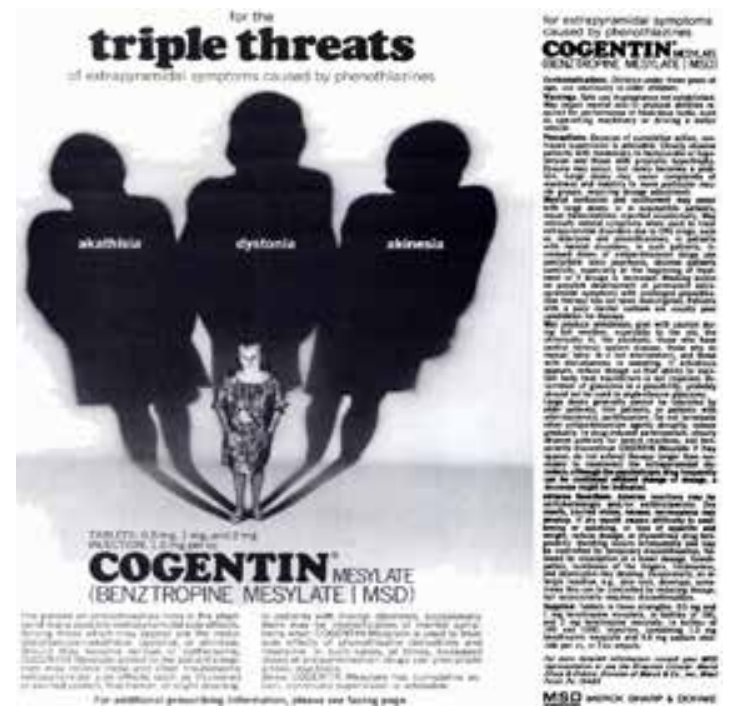

Figura 9 - Publicidade de Cogentin, Lab. Merck (1966, 1972).

Fonte: Procon (2020).

De fato, os antipsicóticos atípicos aparecem para resolver um impasse. A psiquiatria afirmava que "as drogas anteriores eram benéficas, mas problemáticas; as novas drogas representam um avanço em relação às anteriores”. 
Mais uma vez, a hipótese dopaminérgica, que antes fora desestimada, agora voltará com força total.

A risperidona será considerada um antipsicótico que possui poucos efeitos extrapiramidais e maior eficácia comparativamente às doses elevadas de haloperidol, fato que contribuiu para sua rápida incorporação à prática clínica, primeiro nos EUA e logo em todo o mundo. A droga teve um enorme sucesso de vendas na medida em que se apresentava como um novo antipsicótico potente, mas que não tinha os efeitos indesejados dos antipsicóticos clássicos.

A risperidona é um produto do laboratório Janssen, logo adquirido pelo laboratório Johnson \& Johnson. Foi descoberta na Bélgica no final dos anos 1980 por Paul Janssen e colaboradores. Janssen desenvolveu uma nova droga que combinava o bloqueio da dopamina D2 com o receptor 5HT2A, surgindo a risperidona. Em 1986, a droga foi apresentada à FDA, sendo aprovada para venda nos EUA em 1993. Inicialmente essa droga estava destinada ao tratamento de esquizofrenia e psicoses; porém, pouco mais tarde, em 2007, foi aprovada para uso em adolescentes. Contudo, o Risperidal', já era amplamente comercializado e prescrito para crianças e adolescentes antes de ser aprovado para esse uso pela FDA. Em 1989, com dois anos no mercado, a risperidona já passava a responder por $1 / 5$ das prescrições de antipsicóticos nos Estados Unidos, uma tendência que continuou crescendo (WHITAKER, 2010).

Porém, como já foi dito, a risperidona é divulgada e prescrita não só para tratamento de problemas psicóticos, mas também para os chamados distúrbios da infância, tais como Transtorno do Déficit de Atenção com Hiperatividade; Transtorno Desafiador de Oposição; Transtorno Obsessivo-Compulsivo; Autismo.

No Brasil a risperidona foi aprovada para uso infantil em 2014, inicialmente para crianças com autismo. Mais tarde, passou a ser prescrita de maneira ampla para adolescentes diagnosticados com Transtornos de oposição e desafio (TOD). Essa patologia foi migrando para crianças cada vez mais pequenas, até crianças de dois anos de idade, algumas vezes como diagnóstico único e outras vezes como uma comorbidade associada ao autismo ou ao Transtorno de Déficit de Atenção e Hiperatividade (TDAH). 
O certo é que, com o aumento de casos que ingressaram ao amplo campo demarcado pelo (Transtorno do Espectro Autista (TEA), hoje a risperidona é prescrita na primeiríssima infância a crianças de dois anos de idade ou menores, independentemente do fato que, como a própria Bula do medicamento admite: "Não existem estudos sobre o uso de risperidona em crianças menores de 13 anos de idade" (ANVISA, 2018).

A risperidona é também utilizada para crianças diagnosticadas com TDAH, como um auxiliar do tratamento. Sabemos que, no Brasil e no mundo, nos últimos 20 anos, assistimos a um crescimento dramático de crianças diagnosticadas com TDHA; existe um medicamento de uso generalizado para esse diagnóstico que é a Ritalina, cujo princípio ativo é o metilfenidato. Porém, na pesquisa realizada em 2017, por meio de análise de prontuários de crianças e adolescentes de um serviço de saúde mental de São Paulo, denominada $A$ infância na berlinda: Sobre rotulaçóes diagnósticas e a banalização da prescrição de psicofármacos, as autoras, Luana Vizotto e Danielle Ferraza (2017), mostram que existem alguns casos para aos quais se prescrevem dois medicamentos risperidona e Ritalina para o grupo estudado, destacando que $20 \%$ dessas crianças náo tiveram nenhum diagnóstico definido.

O uso da medicação sem ter como referência um diagnóstico, não parece ser estranho quando pensamos que sua função principal é a de ser um potente sedativo. E não, como afirma a bula da droga, um medicamento destinado ao tratamento de transtornos mentais variados como esquizofrenia, psicoses, transtorno bipolar. Em pessoas da terceira idade, a droga é indicada para tratamento de Alzehimer; mas também para o tratamento de crianças agitadas, inquietas e autistas:

Pode ser usada para o tratamento de irritabilidade associada ao transtorno autista, em crianças e adolescentes, incluindo desde sintomas de agressividade até outros, como autoagressão deliberada, crises de raiva e angústia e mudança rápida de humor. (ANVISA, 2018).

Trata-se de uma droga potente que é muito utilizada também para tratamento de dependentes químicos de crack e cocaína (RODRIGUES, 2014). Não deixa de surpreender que um mesmo medicamento possa servir ao mesmo tempo para tratar idosos com Alzheimer, crianças com 
autismo, dependentes químicos, pessoas com transtorno bipolar, mania, esquizofrenia e crianças que se opóem e desafiam as autoridades.

A pergunta que insiste é: "Por que motivo uma criança agressiva, com comportamento irritado, com crises de raiva e angústia, caraterísticas essas que não podem ser identificadas com nenhuma patologia, recebem um antipsicótico poderoso, um sedativo com efeitos colaterais graves como a risperidona?".

Está claro que a literatura médica não falará de controle de comportamentos, mas de terapêutica. Náo fala de crianças agressivas, mas de crianças portadoras de um transtorno, como o TOD. Isto é, a eficácia da risperidona não será apresentada sob o modelo centrado na droga, ocultando-se sua ação como tranquilizante maior, mas sim como um medicamento capaz de curar uma doença. É por esse motivo que o acesso à risperidona, com a finalidade de tratamento de TOD, pode ter ingressado nas políticas do governo pela mediação de protocolos específicos para dispensação da droga; tal como ocorre na cidade de São José do Rio Preto/SP. (SÃO JOSÉ DE RIO PRETO, 2018)

Porém, quando observamos os sintomas que devem ser considerados para diagnosticar o Transtorno de Oposição Desafiante (TOD), cujo código no DSM-5 é 313.81, e no CID-9, F91.3, vemos que é necessário que exista pelo menos quatro dentre os oito sintomas que o DSM-5 apresenta divididos em três grupos:

\section{Humor raivoso/irritável:}

Com frequência perde a calma.

Com frequência é sensível ou facilmente incomodado.

Com frequência é raivoso e ressentido.

\section{Comportamento questionador/ desafiante:}

Frequentemente questiona figuras de autoridade ou, no caso de crianças e adolescentes, adultos. Frequentemente desafia acintosamente ou se recusa a obedecer a regras ou pedidos de figuras de autoridade.

Frequentemente incomoda deliberadamente outras pessoas.

Frequentemente culpa outros por seus erros ou mau comportamento.

\section{Índole vingativa:}

Foi malvado ou vingativo pelo menos duas vezes nos últimos seis meses. (APA, 2013, p. 462). 
Nada indica a existência de algum tipo de doença, nada indica que as crianças inquietas, que perdem a calma ou questionam figuras de autoridade tenham alguma patologia psiquiátrica, nada indica que seja necessário restabelecer um equilíbrio neuroquímico alterado com o uso de um psicofármaco potente como a risperidona. Um fármaco que se apresenta como sendo o primeiro antagonista misto dopamino-serotoninérgico, capaz de agir no bloqueio dos receptores D2, como o haloperidol e a clorpromazina, com menos efeitos extrapiramidais que os antipsicóticos clássicos. Isto é, utiliza-se uma droga potente e perigosa como a risperidona com o argumento de ser a terapêutica indicada para uma patologia de fato inexistente, mesmo que o preço a pagar por essa intervençáo seja altíssimo.

Mencionamos já os efeitos colaterais graves do Risperidal. Desde sempre, os fabricantes da Janssen sabiam que a droga apresentava sérios riscos para a saúde das crianças, tal como afirmam em seu relatório de 2003 sobre risperidona para uso pediátrico: "sua segurança e eficácia em crianças não foi demostrada” (JANSSEN, 2003). Os efeitos colaterais identificados pelo laboratório são discinesia tardia em um grau menor que os antipsicóticos clássicos, efeitos cardiovasculares adversos, hipoglicemia e diabetes, convulsóes e hiperprolactinemia, entre outros sintomas, como a mudança de coloração da pele (icterícia). Por outra parte, como afirma Christopher Lane, diversos estudos recentes mostram que a risperidona, como outros antipsicóticos, devem ser evitados no campo da pediatria porque aumentam o risco de morte em crianças e jovens de 5 a 20 anos (LANE, 2018).

Independentemente desse conhecimento e de avisos reiterados da FDA, a empresa continuou comercializando o medicamento para crianças e adolescentes. Como resposta a uma série de demandas recebidas, a Johnson \& Johnson foi obrigada a pagar US $\$ 2$ bilhóes em multas (ABRASME NOTICIA, 2015). Um valor pouco significativo se considerarmos que a empresa obteve um lucro de quase US \$ 30 bilhóes, no mesmo período, com as vendas da droga.

Pode causar derrames entre os idosos. Pode fazer crescerem seios em meninos; um menino desenvolveu um busto 46DD. No entanto, a Johnson $\mathcal{E}$ Johnson comercializou o Risperdal agressivamente com idosos e crianças, enquanto supostamente manipulava e ocultava os dados sobre o desenvolvimento das mamas. A J E J foi pega, declarou-se culpada de um crime e pagou mais de US $\$ 2$ bilhões em multas e acordos. Mas isso empalidece ao lado dos cerca de US $\$ 30$ bilhões em vendas de Risperdal em todo o mundo. Em suma, o crime compensa, se você é uma grande corporação. (KRISTOF, 2015). 
No relatório anual da Companhia Johnson \& Johnson de 2017, aparece de forma evidente a relevância dos produtos da Janssen para a empresa, do total de 36,3 bilhóes de dólares de venda (o que representa um aumento de $8,3 \%$ em relação a 2016), a rubrica dos psicofármacos representa um total de 6 bilhóes de dólares (JOHNSON \& JOHNSON, 2017), um montante semelhante aos lucros obtidos com medicamentos oncológicos. Os psicofármacos que apresentam recorde de vendas são de três tipos: novos antipsicóticos, como Xeplion', Trinza e Trevicta ${ }^{\circ}$ e dois medicamentos fortemente prescritos em crianças indisciplinadas, com dificuldade de aprendizagem ou com problemas de comportamento: Concerta (metilfenidato) e risperidona.

É verdade que houve uma diminuição das vendas entre os anos de 2015 e 2017, vinculada, sem dúvida, à ampla divulgação que tiveram os processos jurídicos vencidos pelos pacientes que se sentiram lesados pela droga. Os processos mais famosos e milionários estáo vinculados à hiperprolactinemia provocada em homens ou jovens pela droga. Porém, como afirma o relatório, as perdas foram muito bem compensadas com o aumento de vendas dos outros antipsicóticos.

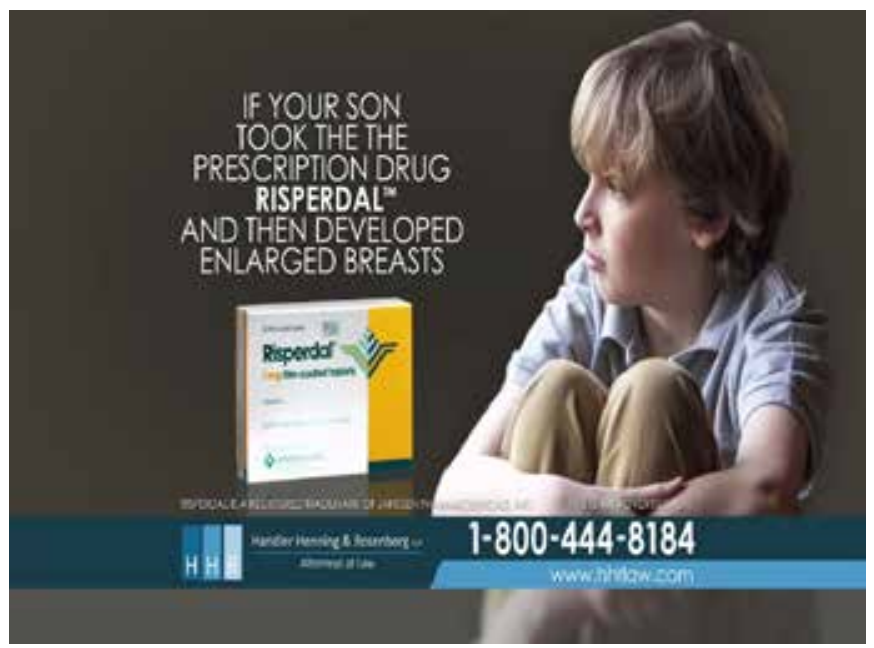

Figura 10 - Handler Henning e Rosemberg, Attorneys at Law. Advertising. Fonte: https://www.youtube.com/watch?v=gV4JTI4mKys. 
O anúncio da Figura 10 mostra a existência de um mercado paralelo de suporte legal para familiares de crianças que sofreram o efeito colateral da hiperprolactina, isto é, crescimento de peitos e produçáo de leite, em meninos.

Constatamos que, ainda que a risperidona tenha uma ação semelhante à clorpromazina - tranquilizante que reduz a atividade intelectual e emocional, e que, apenas em alguns casos, pode reduzir as alucinaçóes e delírios -, trata-se de uma droga que tem consequências perduráveis referentes ao aumento da cronicidade, à deterioração funcional, à degradaçáo cognitiva e à aparição de doenças físicas evitáveis vinculadas ao ganho de peso, diabetes, hipertensão etc. (FREITAS; AMARANTE, 2015; WHITAKER, 2015).

Assim, tanto em relação à clorpromazina como em relação à risperidona, quando analisarmos essas drogas a partir de uma perspectiva centrada no fármaco, poderemos concluir que, longe de ter um efeito terapêutico de cura ou melhoria de sintomas, o que pode ser observado quando existe uso contínuo da medicação, de acordo com um artigo publicado em Schizophrenia Bulletin, referenciado por Whitaker (2015, p. 138), é a multiplicação de novos sintomas. Em longo prazo,

[...] o bloqueio do receptor D2 desestimula a reação em todos os acontecimentos da vida cotidiana, provocando uma anedonia química que se rotula às vezes como depressão pós-psicótica ou disforia neuroléptica [...]. Liberamos os pacientes do manicômio com agentes bloqueadores do receptor D2 só para bloquear o incentivo, a conexão com o mundo e a joie de viure da vida diária? A medicação pode salvar a vida do paciente em uma crise, mas pode fazê-lo mais propenso a psicoses se a medicação é retirada, e mais acossado pelo déficit se se mantém a medicação.

Esse parece ser o alto preço a pagar para que os neurolépticos possam ser considerados como terapeuticamente eficazes. Pode-se afirmar que, tanto no caso da clorpromazina como no da risperidona, o que se avalia como eficácia terapêutica não é outra coisa que a imposição da calma, do silêncio e da disciplina - seja dentro das enfermarias e salas de pacientes agitados no asilo, seja na sala de aula ou no cotidiano de crianças agitadas e indisciplinadas.

\section{A modo de conclusão}

Para concluir, é preciso lembrar que, no mês de outubro de 2019, a corte de Filadélfia obrigou a Johnson \& Johnson a pagar a soma de 8 
milhóes de dólares a um jovem de 26 anos, Nicholas Murray, que sofreu os efeitos adversos da risperidona que resultaram em um problema de ginecomastia, uma condição masculina resultante da hipertrofia das glândulas mamárias. Murray tinha iniciado o tratamento no ano 2003, quando tinha 10 anos de idade. Janssen, subsidiária de Johnson \& Johnson afirma que apelará a sentença que considera desproporcional (BBC NEWS, 2019).

Portanto, se renunciarmos a pensar os neurolépticos de acordo como modelo centrado na doença, poderemos afirmar que tanto a clorpromazina como a risperidona fazem parte dos dispositivos biopolíticos de gestão dos comportamentos cotidianos socialmente indesejados. Tal como afirma Joanna Moncrieff (2017), referindo-se ao mito do desequilíbrio cerebral, muitos profissionais e pacientes consideram como uma evidência e estão falsamente convencidos de que o desequilíbrio neuroquímico é o que provoca o sofrimento mental. No entanto, não só estão ausentes as evidências de que exista uma base biológica definida para cada transtorno psiquiátrico, hoje sabemos também de que modo as drogas alteram e afetam o cérebro. De acordo com Breggin (2016, p. 14), elas trabalham "desabilitando" parcialmente o cérebro: "Nenhuma substância psicoativa corrige desequilíbrios bioquímicos ou transtornos do cérebro. Nenhuma melhora a função do cérebro ou da mente. $\mathrm{O}$ efeito terapêutico produz sempre uma incapacidade". Mais tarde, a psiquiatria e a indústria farmacêutica se encarregaram de redefinir esses danos cerebrais (brain injury) provocados pelos psicofármacos, como sendo um efeito terapêutico desejado. Um efeito que, no entanto, desarticula a polaridade entre o indivíduo e seu meio, produzindo doença.

Os antipsicóticos aqui analisados apresentam um bom exemplo do modo como opera a indústria farmacêutica no incremento das taxas de transtornos mentais na população, nesse caso transformando em patológicos comportamentos comuns na sociedade, tais como: perder a clama, ficar com raiva, sentir-se incomodado, resistir às ordens das autoridades ou dos adultos. Comportamentos que o Manual de Diagnóstico e Estatística de Transtornos Mentais (DSM) transformou em sintomas psiquiátricos e que a indústria farmacêutica se encarregará de difundir e popularizar pela mediação do auxílio a pesquisadores, financiamentos de pesquisas, divul- 
gação em congressos médicos, e um imenso aparelho de publicidade direta e indireta. De fato, a indústria farmacêutica ocupa apenas uma parte desse complexo tecido da psiquiatrização da infância. Pois, para que a prescrição de antipsicóticos com efeitos adversos graves pudesse tornar-se aceitável e legítima, foi preciso que, inicialmente, as categorias propostas pelo DSM conquistassem respeitabilidade, aceitação e reconhecimento como discurso científico. Isto é, foi preciso que o tratamento farmacológico, nesse caso com antipsicóticos, fosse apresentado de acordo com o modelo centrado na doença (MONCRIEFF, 2013b). Isso ocorre mesmo se em doenças, como o TOD, definidas de acordo com critérios diagnósticos ambíguos estabelecidos pelo DSM-5. Onde são elencados sintomas que estão claramente vinculados a comportamentos indesejados mais que a qualquer patologia psiquiátrica.

\section{Referências}

ABRASME NOTICIA. Mais de mil meninos tiveram seus seios crescidos, causa provável a risperidona 02/02/2015. ABRASME, [s. l.], p. 1-2, 2015.

AGÊNCIA NACIONAL DE VIGILÂNCIA SANITÁRIA (ANVISA). Bula Amplictil. [S. l.]: Anvisa, 2018. Disponível em: http://www.saudedireta.com.br/catinc/drugs/bulas/amplictil.pdf. Acesso em: 10 set. 2020.

AGÊNCIA NACIONAL DE VIGILÂNCIA SANITÁRIA (ANVISA). Quadro 1. Resumo de indicaçóes de antipsicóticos e uso na faixa etária pediátrica de acordo com as respectivas bulas brasileiras. [S. l.]: Anvisa, 2014.

AMERICAN PSYCHIATRIC ASSOCIATION (APA). Diagnostic and Statistical Manual of Mental Disorders, Fifth Edition (DSM-5). Arlington. Arlington: American Psychiatric Association, 2013.

BBC NEWS. Risperdal, el fármaco por el que Johnson \& Johnson deberá pagar US \$ 8.000 millones a un joven a quien le crecieron los pechos Efectos colaterales adversos. 9 out. 2019 Disponível em: https://www.bbc.com/mundo/noticias-49987187. Acesso em: 10 set. 2020.

BREGGIN, P. Medication Madness. New York: St. Martin’s Press, 2008.

BREGGIN, P. Toxic Psychiatry. New York: St. Martin’s Press, 1991.

BREGGIN, P. Rational Principles of Psychopharmacology for Therapists, Healthcare Providers and Clients. Journal of Contemporary Psychotherapy, v. 46, n. 1, p. 1-13, 2016.

CAPONI, S. Uma sala tranquila: antipsicóticos para uma biopolitica da indiferença. São Paulo: LiberArs, 2019. 
BOURGUIGNON, A.; DELAY, J.; DENIKER, P.; LEMPERIERE, T. Extrapyramidal movement disorders during chlorpromazine and reserpine therapy. Encephale, v. 45, n. 4, p. 1093-1098, 1956.

DELAY, J; DENIKER, P. Utilisation en Therapeutique psychiatrique d'une phenithiazine d'action centrale élective (4560 RP). Annales médico-psychologiques, v. 110, n. 2, p. 112-131, 1952.

DENIKER, P. Psychopharmacologie. Les médicaments et drogues psychotropes. Paris: Ellipses, 1987.

FREITAS, F; AMARANTE, P. Medicalizaçáo em psiquiatria. Rio de janeiro: FIOCRUZ, 2015.

GALARCE, M. Uso de risperidona em nińos. Pontificia Universidad católica del Chile, 2008. Disponível em: https://medicina.uc.cl/publicacion/uso-de-risperidona-en-ninos-efectividad-yperfil-de-seguridad/. Acesso em: 10 set. 2020.

GOTSZCHE, P. Psicofármacos que matam y denegación organizada. Barcelona: Los libros del lince, 2016.

HANDLER, HENNING E ROSEMBERG, Attorneys at Law. Advertising. Disponivel em https:// www.youtube.com/watch?v=gV4JTl4mKys. Acesso em, 23 de setembro de 2020.

INSEL, T. Rethinking schizophrenia. Nature v. 468, n. 7321, p. 187-193, 2010.1476-4687 (Electronic)n0028-0836 (Linking).

JANSSEN. RISPERIDAL Products L. P. [S. l.]: Janssen, 2003.

JOHNSON \& JOHNSON. Annual Report 2017. 2017. Disponível em: https:/www.jnj. com/2017-year-in-review. Acesso em: 10 set. 2020.

KRISTOF, N. When Crime Pays : J \& J's Drug Risperdal. New York Times, n. September 17th, p. 1-3, 2015.

LANE, C. H. Antipsychotics Tied to Higher Risk of Death in Children. 2018. Disponível em: https://www.psychologytoday.com/intl/blog/side-effects/201812/antipsychotics-tied-higher-riskdeath-in-children. Acesso em: 10 set. 2020.

MAGALHĀES BRAGA, A. Uso de psicofármacos na Infância e na Adolescência para o pediatra geral. Brasília Médica, v. 48, n. 3, p. 299-307, 2011.

MONCRIEFF, J. Hablando claro: una introducción a los fármacos psiquiatricos. Barcelona: Herder, 2013a.

MONCRIEFF, J. Magic bullets for mental disorders: the emergence of the concept of an "Antipsychotic" drug. Journal of the History of the Neurosciences v. 22, n. 1, p. 30-46, 2013b.

MONCRIEFF, J. Models of drug action. 2013c. Disponível em: https://joannamoncrieff. com/2013/11/21/models-of-drug-ation/. Acesso em: 10 set. 2020.

MONCRIEFF, J. The Myth of the Chemical Cure. London: Palgrave MacMillan, 2008. 
MONCRIEFF, J. Las incómodas verdades acerca de los antipsicóticos : una respuesta a Goff et al. Mad in América, 2017. Disponível em: http://madinamerica-hispanohablante.org/las-incomodasverdades-acerca-de-los-antipsicoticos-una-respuesta-a-goff-et-al-joanna-moncrieff/. Acesso em: 10 set. 2020 .

MONCRIEFF, J.; COHEN, D. Rethinking models of psychotropic drug action. Psychotherapy and Psychosomatics, v. 74, n. 3, p. 145-153, 2005.

MONCRIEFF, J.; MIDDLETON, H. Schizophrenia: A critical psychiatry perspective. Current Opinion in Psychiatry, v. 28, n. 3, p. 264-268, 2015.

NEW drug hailed as tranquilizer. 550 Patients Are Calmed by Promazine - No Side Reactions Noted in Test. The New York Times, New York, p. 25, 1956.

PIGNARRE, P. Les malheurs des psys: psychotropes et médicalisation du social. Paris: La Découverte, 2006.

PLUMB, R. Drug Use. New York Times, p. 1, 1955 a.

PLUMB, R. Drug use hailed in mental cases; State Hospitals Report Big Therapeutic Gains With the New Compounds. The New York Times, 1955b.

PLUMB, R. Tranquil wards show drugs' help. The New York Times, p. 1956, 1956.

PROCON.ORG. Prescription Drugs Advertising. 2020. Disponível em: https://prescriptiondrugs. procon.org. Acesso em: 10 set. 2020.

RODRIGUES, A. Ministério da Saúde estuda distribuir risperidona a usuários de crack e cocaína. Agencia Brasil, p. 1-5, 2014.

SECRETARIA DE SAÚDE SÃO JOSÉ DE RIO PRETO (SP). Protocolo de tratamento de transtornos desafiador opositor e transtorno de conduta - Risperidona. 2018. Disponível em: http://saude.riopreto.sp.gov.br/transparencia/arqu/arqufunc/2018/risperidona_tod.pdf. Acesso em: 10 set. 2020 .

SERENITY Drugs disturb doctors. Side Effects in Treatment of Mentally Ill Are Cited at Manufacturers' Meeting. The New York Times, New York, p. 3, 1955.

TCHEREMISSINE, O.; LIEVING, L. Pharmacological Aspects of the Treatment of Conduct Disorder in Children and Adolescents. Terapy in Practice, v. 20, n. 7, p. 549-565, 2006.

UPS and Downs With Pills. The New York Times, New York, v. 23/6, p. 1957, 1957.

VIZOTTO, L.; FERRAZZA, D. Childhood in the hotseat: On diagnostic labeling and the trivialized practice of psychotropic prescriptions. Estudos de Psicologia, v. 22, n. 2, p. 214-224, 2017.

WHITAKER, R. Mad in America. Bad Science, bad medecine, and the enduring mistratment of the mentallu ill. New York: Basic Books; Membrer of Perseus Books Group, 2010. 
WHITAKER, R. Anatomia de uma epidemia. Medicamentos psiquiátricos y el asombroso aumento de las enfermedades mentales. Madrid: Ed. Capitan Swing, 2015.

WHITAKER, R. La psiquiatría defiende sus antipsicóticos: Un caso práctico de corrupción institucional - Robert Informe MIA: La psiquiatría defiende sus antipsicóticos . Un caso práctico de corrupción institucional, 2017. p. 6-8.

Recebido: 05/06/2020

Aceito: 22/06/2020 


\section{The psychopharmacologization of childhood and the Disease centered model of drug action}

\section{Abstract}

The prescription and wide acceptance of the use of classic and atypical antipsychotics in childhood and adolescence was legitimated by relying on the supposed therapeutic and curative functions of these drugs. Taking as a starting point the distinction of two explanatory models of action of psychoactive drugs, one centered on the disease and the other centered on the drug, I analyze how the pharmaceutical industry has contributed, with its marketing strategies, to the dissemination of a triumphalist narrative that naturalized the use of antipsychotics as a cure for psychiatric diseases. The two psychopharmaceuticals analyzed are chlorpromazine, a classic antipsychotic, and risperidone, an atypical, state-of-the-art antipsychotic.

Keywords: Classic antipsychotic. Atypical antipsychotic. Childhood. Pharmaceutical industry. Medicalization. 